\title{
Allergic reactions after vaccination: translating guidelines into clinical practice
}

\author{
${ }^{1}$ SOS Allergologia e Immunologia, Firenze, Azienda USL Toscana Centro, Italy \\ ${ }^{2}$ SOS Allergologia e Immunologia, Prato, Azienda USL Toscana Centro, Italy
}

\begin{abstract}
KEYWORDS
vaccine; vaccination; allergic reactions; anaphylaxis; vaccine hesitancy; vaccine components; desensitization
\end{abstract}

\author{
Corresponding author \\ Anna Radice \\ Ospedale San Giovanni di Dio \\ Via Torregalli 3, 50143 Firenze \\ Phone: +39055 6932304 \\ E-mail: anna.radice@uslcentro.toscana.it
}

\section{Doi}

10.23822/EurAnnACI.1764-1489.86

\begin{abstract}
Summary
Vaccination represents one of the most powerful medical interventions on global health. Despite being safe, sustainable, and effective against infectious and in some cases also non-infectious diseases, it's nowadays facing general opinion's hesitancy because of a false perceived risk of adverse events. Adverse reactions to vaccines are relatively rare, instead, and those recognizing a hypersensitivity mechanism are even rarer.

The purpose of this review is to offer a practical approach to adverse events after vaccination, focusing on immune-mediated reactions with particular regard to their recognition, diagnosis and management.

According to clinical features, we propose an algorythm for allergologic work-up, which helps in confirming hypersensitivity to vaccine, nonetheless ensuring access to vaccination. Finally, a screening questionnaire is included, providing criteria for immunisation in specialized care settings.
\end{abstract}

\section{Introduction}

"Smallpox is dead" stated the magazine of the World Health Organisation (WHO) in 1980. It was the first time that a high contagious and dangerous disease was globally eradicated. And the credit went to an extensive worldwide immunisation campaign, begun in 1967, combined to highly organised prevention and surveillance measures. Once again, the vaccines showed their indisputable efficacy $(1,2)$.

To date, vaccines are considered one of the most powerful public health interventions that have contributed to the drastic reduction of the mortality and the morbidity of several infectious diseases (3). Moreover, vaccines have also demonstrated a primary role in preventing virus-associated malignancies, such as HPV-driven cervical cancer (4).

Vaccination saves between 1 and 3 million lives worldwide every year. According to the World Health Organisation, vaccines will save 25 million more lives in the coming decade (adapted from: 5). One of the primary aims of WHO is giving equitable access to vaccines, collected under the name of Global Vaccine Action Plan (GVAP) (6).
The gain from vaccination is not just about human health, but it is also a matter of financial resources for health systems. It has been calculated that for every dollar spent in vaccines, 16 dollars (US \$) are expected to be saved in healthcare costs, loss of productivity and incomes (7). Even before, several studies had assessed the cost-benefits of immunisation (8). A loss of more than 60 billion dollars (direct and indirect costs) has been quantified in a hypothetical unvaccinated cohort of three million children in the US (9). Recently, after the introduction of new expensive vaccines and the global financial crisis, a better standardization in the scientific works regarding the topic "cost-benefits" has been advocated, since most of them differ in adopted methodologies $(10,11)$.

In 2018 the European Commission, in agreement with WHO, has reiterated the importance of reaching and maintaining high level of coverage rate of vaccination. The pillars of its proposal included a better financial sustainability and a "tackling vaccine hesitancy" strategy $(12,13)$. Vaccine hesitancy is a recent phenomenon, typical of Western countries, consisting in refusing or delaying an available vaccination (14), that has led to an alarming reduction in coverage rate. The 
case of measles best resumes the consequence of the "vaccine hesitancy". In the European Vaccine Action Plan for 20152020, WHO aimed at eradicating measles (15). However, the gradual decrease of vaccination against this infection resulted in a resurgence of measles with several outbreaks, 14,600 cases and 37 deaths in the European area in 2017. The highest incidence was observed in children aged $<4$ years, especially $\leq 1$ year, and most of the cases occurred in unvaccinated subjects, reaching a rate of $96 \%$ in children aged $\leq 1$ year (16). In December 2018 the European Centre for Disease Prevention and Control (ECDC) reported 34 fatalities due to measles in 2018 (17). Hence, the goal of the European Commission regarding measles has now turned into "reaching at least a coverage rate of $95 \%$ ".

Although vaccine hesitancy is a multi-layered phenomenon, safety of vaccination is one of its most relevant cofactors. Injecting a potentially dangerous organism in a healthy subject is intuitively experienced as a danger (14); that encourages distrust towards vaccines, especially if false or real claims of adverse reactions are widespread. A striking example was that of Wakefield. His fraudaulent study supporting the association between measles-mumps-rubella vaccine and autism was definitively disproved with heavy consequences for the author, but nevertheless this misinformation still troubles those skeptical towards vaccines (18). Moreover, unlike their parents and grandparents, new generations in Western countries have no confidence with epidemics and their potential consequences. And it has been demonstrated that perceiving more the risks than the benefits of immunisation favours the reluctance against vaccines (19).

Hence, it is necessary to reduce this false perception of unsafety and even uselessness regarding the immunisation. Also, the introduction of new vaccines has required better tools to analyse their real impact on subject's health, as mentioned above. Scientific societies, drug agencies and major health organisations have created several active vaccine-pharmacovigilance entities and working groups. The Vaccine Adverse Event Reporting System (VAERS) in the US (20) or pharmacovigilance section of EMA, for example, regularly collect reports and cooperate with governments in the field of vaccination. The "unmet needs" regarding vaccination is the field of interest of the Working Group on Vaccine Safety (WG), a subgroup of the Council for International Organizations of Medical Sciences (CIOMS), an organization established by the WHO and UNESCO in 1949 (21). There are several working groups dedicated to support research, produce guidelines, organise trainings and offer precise information (for example, the Vaccines Working Party, VWP) (22).

This has led to a better knowledge of the pathogenic mechanisms of the AEFI (Adverse Events Following Immunisation) until the discover of immune-mediated reactions, including allergic ones. Over the time, more and more knowledge has been collected, and to date allergological diagnostic tests and even desensitization protocols are available. Notwithstanding the rarity of allergic events following vaccination, they can be harmful for at least two reasons: first, severe allergic reactions such as anaphylaxis could be life threatening; second, a real, presumed or even feared allergy to vaccines limits or delays the accessibility to a regular immunisation program.

Here we propose a practical approach to AEFI from an allergological point of view aimed at identifying risk factors, diagnosing allergies and providing a framework to ensure vaccination, according to the subjects' risks, either in a standard care or in specialized centres. A better selection of patients requiring an allergological in case of AEFI is necessary to properly address health resources.

\section{Definitions}

Adverse event following immunization (AEFI) is "any untoward medical occurrence which follows immunization and which does not necessarily have a causal relationship with the usage of the vaccine" (23). The Working Group on Vaccine Safety has classified AEFI in 5 groups:

- vaccine product-related reactions: caused or precipitated by a vaccine due to one or more of the inherent properties of the vaccine product;

- vaccine quality defect-related reactions: caused or precipitated by a vaccine due to one or more quality defects of the vaccine product, including the administration device, as provided by the manufacturer;

- immunization error-related reactions: caused by inappropriate vaccine handling, prescribing or administration and that therefore, by its nature, is preventable;

- anxiety-related reactions: arising from anxiety about the immunization;

- coincidental events: caused by something other than the vaccine product, immunization error or immunization anxiety.

Vaccine product- and quality defect-related reactions are those potentially involving immune system, summarized in table I according to the latest document of CIOMS.

Classification in systemic and local could help the physician in a faster differential diagnosis between allergic and non-allergic reactions in daily-clinical practice (table II). The term "allergy" encompasses all 4 types of reactions according to Gell and Coombs. (25).

Classifying reactions according to timing is also extremely important to better understand their nature: i) immediate type occurs within minutes and usually no more than after 4 hours; ii) delayed type occurs hours to days (up to 2-3 weeks) after vaccination (26). 


\section{Table I - Vaccine product and quality defect related.}

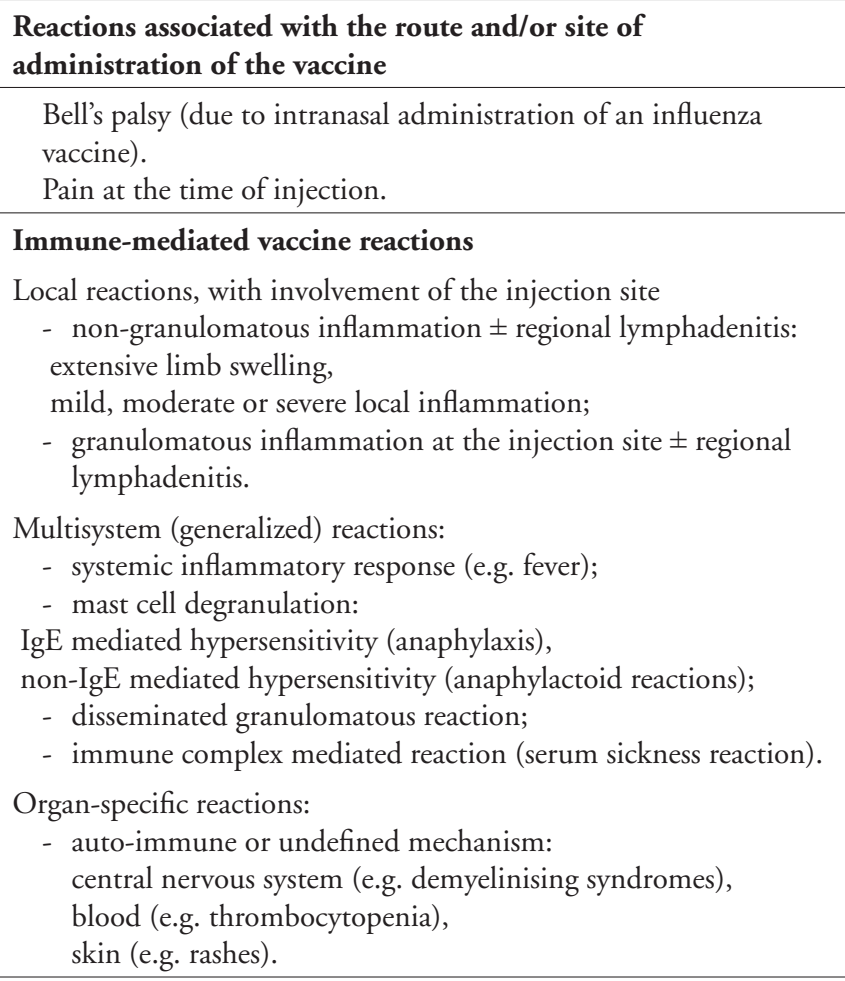

Reactions as a consequence of replication of vaccine-associated microbial agent(s)

For example:

- an attenuated vaccine agent;

- a wild-type vaccine agent due to insufficient inactivation during the manufacturing process;

- a contaminant introduced into vaccine during the manufacturing process.

Direct toxic effect of a vaccine component or contaminant e.g. Quality defect. Adapted from (24).

\section{Allergic reactions}

\section{Epidemiology of allergic reactions}

Allergic reactions to vaccines are extremely rare. In a recent review, the World Allergy Organisation reports an estimated rate of allergic reactions from 1 in 50,000 to 1 in 1,000,000 and of anaphylaxis of 1 in 100,000 to 1 in 1,000,000 (31).

Each vaccine shows different incidences of hypersensitivity reactions, including anaphylaxis (table III).

In 2009 an unusual higher incidence of anaphylaxis and allergic reactions with $\mathrm{H} 1 \mathrm{~N} 1$ vaccines was reported, with a rate of incidence 3.3 greater than the previous immunisation cam-

Table II - Clinical classification of AEFI.

\begin{tabular}{ll}
\hline Local Reactions & Potential Mechanism \\
\hline $\begin{array}{l}\text { Mild local reactions: Pain, } \\
\text { redness, and/or swelling at } \\
\text { injection site } \\
\text { Large local reactions }\end{array}$ & Non specific inflammation \\
& $\begin{array}{l}\text { Most non allergic }{ }^{\text {a }} \text { sometimes } \\
\text { Exthus reactions. }\end{array}$ \\
Subcutaneous nodules & Not allergic \\
Local eczema lesions & $\begin{array}{l}\text { Allergic (type 4) and not } \\
\text { allergic }\end{array}$ \\
\hline
\end{tabular}

\section{Systemic Reactions}

Fever, irritability, malaise, diarrhea, headache, muscle pains

Syncope, vasovagal reaction, anxiety disorders

Anaphyloctoid reactions

Anaphylaxis

Serum sickness reaction

Organ specific:

- Blood: Trombocytopenia, anemia, leucopenia

- Skin: non specific rashes, immediate and delayed angioedema/urticarial, macopapular rash, systemic eczema, SCAR

- Nervous system: Guillian Barrè, Allergic demyelinising syndromes

Reactions depending on microbial activity

e.g Varicella vaccine-strain viral Not allergic reactivation

SCAR, severe cutaneous adverse reactions; ${ }^{2}$ Risk factors, HBV; Pneumococcal and Haemophilus influenzae; high concentration of toxoids (tetanus, diphtheria, Bordetella pertussis) and aluminium hydroxide $(27,28,29,30)$.

paign. The responsible was an adjuvant (AS03) added to the last vaccine slot (32).

\section{Aetiology}

Immediate $\operatorname{IgE}$ mediated allergic reactions to vaccines are rare and occur less frequently than delayed reactions (see below). Anyway, detection of $\mathrm{IgE}$ responses after vaccination is very common, and involves more than $90 \%$ of infants after a booster or vaccine. (42). Atopic children show a higher tendency towards this phenomenon (43) even if a higher incidence of anaphylaxis has not been demonstrated in these subjects $(44,45)$. 
Table III - Anaphylaxis incidence among different vaccines.

\begin{tabular}{|c|c|}
\hline Vaccine & Anaphylaxis incidence \\
\hline $\mathrm{DTaP}$ & $\begin{array}{l}0.95 \text { million doses }^{33} \\
0.36 / 100.000 \text { doses }^{34} \\
2.07 / \text { million doses }^{35}\end{array}$ \\
\hline Influenza & $\begin{array}{l}7 \text { over } 3.3 \text { million doses (IIV) } \\
0 \text { among } 232.406 \text { doses (LAIV) }\end{array}$ \\
\hline MMR & $\begin{array}{l}0.06 / 100,000 \text { doses }^{37} \\
5.14 / \text { million doses }^{35}\end{array}$ \\
\hline Varicella & $0 / 1.3$ million doses $^{38}$ \\
\hline YF & $0.42-1.8 / 100.000$ doses $^{39}$ \\
\hline Men ACWY & 7 suspected anaphylaxes among 8.2 million doses ${ }^{40}$ \\
\hline $\mathrm{HPV}$ & 2.6/100.000 doses ${ }^{41}$ \\
\hline \multicolumn{2}{|c|}{$\begin{array}{l}\text { DTaP, Diphtheria, Tetanus, acellular Pertussis; YF, yellow fever; MMR, mea- } \\
\text { sles, mumps, rubella; HPV, Human papilloma Virus; IIV, Inactivated Influenza } \\
\text { vaccine; LAIV, live attenuated influenza vaccine; LAMV, live attenuated mon- } \\
\text { ovalent influenza vaccine (LAMV); Men ACWY, meningococcal vaccine groups } \\
\text { A, C, W-135, Y. } \\
\text { Except for notes (40) and (41), notes from (33) to (39) are adapted from notes } \\
\text { (28) and (31). }\end{array}$} \\
\hline
\end{tabular}

Several components of a vaccine may elicit hypersensitivity reactions, although with different incidence and clinical features $(28,29,31)$.

Microbial antigens:

- toxoids (tetanus and diphtheria). After the introduction of highly purified toxoids, the incidence of anaphylaxis has significantly decreased $(46,47)$. Recently, the discovery of traces of cow's milk in diphtheria and tetanus vaccines has suggested milk allergy involvement in the cases of anaphylaxis (see below) (48);

- the mutant, non-toxic form of diphtheria toxin (CRM (197) is a component of some conjugated vaccines, and has been implicated in two cases of allergic reactions: one with prevenar- $13^{\circledR}$ (45) and the other with haemophilus influenzae B (49);

- virus-like particles of HPV could favor anaphylaxis (50), triggered by polysorbate 80 (stabilizer of quadrivalent vaccine) (51).

Stabilizers:

- porcine and bovine gelatin, traceable in vaccines against measles/mumps/rubella (MMR, old brands), varicella, influenza and tick borne encephalitis (28). In the past decades, MMR vaccines contained higher quantities of gelatin and episodes of anaphylaxis were much more frequent (31);

- Dextran, which has been withdrawn from the market.

Adjuvants and preservatives:

- thimerosal, formaldehyde, phenoxyethanol, aluminium hydroxide an aluminium phosphate are the most well known. They are usually associated to delayed cutaneous reactions (28). To date the use of thimerosal has dropped due to its mercury content (52);
- new adjuvants have been introduced such as polysorbate 80 (HPV) (53). Cases of suspected IgE-mediated reactions have been documented in H1N1 influenza vaccines due to squalene adjuvant AS03 (32).

Residual contaminants (of the culture medium):

- ovalbumin from hen's egg in yellow fever vaccine reaches potentially risky concentrations. Other vaccines containing ovalbumin are influenza, MMR, tick-borne encephalitis, some rabies vaccines (28);

- yeast proteins from Saccharomyces cerevisiae have been reported in quadrivalent human papilloma virus vaccine (HPV) (54), potentially in Hepatitis B (54), in PCV13 and in some meningococcal and oral typhoid vaccines (55);

- cow's milk proteins, in some brands of diphteria, tetanus and pertussis vaccines, oral polio vaccine (56);

- antibiotics such as neomycin B (57), polymyxin B, gentamycin, streptomycin (29).

Latex:

- from vaccine vials (e.g. HBV) or syringe plungers (28).

Alpha gal:

- contained in porcine gelatin or cow's milk residual, has been recently implicated in a case of anaphylaxis after zoster vaccine in a patient with known red meat allergy (58).

\section{Clinical features}

Allergic reactions can be local and systemic and are summarized in table I and II.

Types of local allergic reactions are:

- Arthus reaction: is a large local reaction depending on the injection of a vaccine whose antigens encounter their specific IgG in a subject with pre-existing immunisation (59);

- local eczema lesions: especially in those patients sensitized to contact allergens such as aluminium salts, thimerosal, formaldehyde, neomycin;

Systemic allergic reactions:

- IgE mediated: Anaphylaxis (see figure 1 for the definition of anaphylaxis);

- Delayed type reactions, with involvement of different organs and systems.

\section{Clinical management of reactions}

Immunisation should be performed by health care professionals, certified in cardiopulmonary resuscitation (CPR), provided and familiar with an onsite emergency protocol. Low risk immunisation procedures are conducted at general practitioners or pediatricians' office or at vaccination centers, where expertise and equipment such as adrenaline, antihistamines, oral steroids, beta2-inhalers, oxygen and devices in case of emergency must be assured. High risk patients should under- 
go immunisation in a controlled setting where expert personnel are available to manage anaphylactic reactions providing advanced life support. Observation time after immunization, usually 15 minutes, should be prolonged according to individual risk (61-63;28).

\section{Management of reactions}

Local reactions can be limited to injection site or extended to the limb and most frequently develop as delayed painful, swelling lesions with erythema or eczema, sometimes as subcutaneous nodules. Patients or caregivers should be advised to apply a cold cloth at the injection site and use paracetamol as pain killer up to $15 \mathrm{mg} / \mathrm{kg}$ every 6-8 hours (27). Subcutaneous granulomas are benign itchy erythematous waxing and waning masses, secondary to hypersensitivity reactions to alum-adjuvanted vaccines, which can be treated with oral antihistamines and topical steroids (64). As for systemic reactions, it is important for health workers to be able to distinguish between panic, vasovagal and hypotonic hyporesponsive reactions and anaphylaxis (see table IV Differentiation of anaphylaxis and vasovagal reaction in EAACI position paper, (28)). Anaphylaxis is defined and diagnosed according to Sampson's criteria (figure $\mathbf{1}$ ) and acute management requires immediate intramuscolar epinephrine administration and ABCDE assessment, as stated in EAACI anaphylaxis guidelines (60). Although the Joint Task Force on Practice Parameters (JTFPP) guidelines identify a 4-hour cut-off for allergic-like events after immunization (ALE), proper anaphylactic reactions rarely occur more than one hour after vaccine administration, so it should be safe enough to restrict subsequent thorough allergological work up to patients with onset of symptoms up to one hour or anaphylaxis, according to the clinical approach proposed by Zafack et al. (65-67). Individual cases of AEFI must
Table IV - Useful information for the management of vaccine allergy.

A complete list of allergens and where they can be found is available on http://www.vaccinesafety.edu/components-Allergens.htm

A list of vaccine potentially at risk for latex allergy is available on http://www.cdc.gov/vaccines/pubs/pinkbook/downloads/ appendices/B/latex-table.pdf

Traceable excipients and media in vaccines are listed on https://www.cdc.gov/vaccines/pubs/pinkbook/downloads/ appendices/B/excipient-table-2.pdf

Accessed in January 2019.

be reported to regulatory authorities in each country, working in the framework of international Centers for Disease Control and other stakeholders.

\section{Patients with suspected hypersensitivity reactions}

In patients reporting a previous reaction to a vaccine, case history should be collected in order to assess symptoms, time intervals and treatment needed for resolution. Medical history should focus on specific questions like the presence of previous documented allergy to foods, contact allergy, latex allergy and/or previous reactions to vaccines. A causality checklist has been developed by the Global Advisory Committee for Vaccine Safety (GACVS) of World Health Organization (68) as a tool to establish a causal relationship between the clinical event and immunisation. Immediate reactions with timing and characteristics of allergic symptoms are generally easier to be attributed to vaccine hypersensitivity.

Risk of recurrence of serious adverse events has not been thoroughly studied in high risk patients for ethical reasons, but pa-

\section{Figure 1 - Anaphylaxis definition.}

Anaphylaxis is highly likely when any one of the following three criteria is fulfilled:

1. Acute onset of an illness (minutes to several hours) with involvement of the skin, mucosal tissue, or both (e.g., generalized hives, pruritus,

or flushing, swollen lips-tongue-uvula) and at least one of the following:

- respiratory compromise (e.g., dyspnoea, wheeze-bronchospasm, stridor, reduced PEF, hypoxemia);

- reduced BP or associated symptoms of end-organ dysfunction (e.g., hypotonia [collapse], syncope, incontinence).

2. Two or more of the following that occur rapidly after exposure to a likely allergen for that patient (minutes to several hours):

- involvement of the skin-mucosal tissue (e.g., generalized hives, itch-flush, swollen lips-tongue-uvula);

- respiratory compromise (e.g., dyspnoea, wheeze-bronchospasm, stridor, reduced PEF, hypoxemia);

- reduced BP or associated symptoms (e.g., hypotonia [collapse], syncope, incontinence);

- persistent gastrointestinal symptoms (e.g., crampy abdominal pain, vomiting).

3. Reduced BP after exposure to known allergen for that patient (minutes to several hours):

- infants and children: low systolic BP (age-specific) or $>30 \%$ decrease in systolic BPa;

- adults: systolic BP of $<90 \mathrm{~mm} \mathrm{Hg}$ or $>30 \%$ decrease from that person's baseline.

PEF, Peak expiratory flow; BP, blood pressure. ${ }^{2}$ Low systolic blood pressure for children is defined as $<70 \mathrm{~mm} \mathrm{Hg}$ from 1 month to 1 year, less than (70 mm $\mathrm{Hg}+$ [2× age]) from 1 to 10 years, and $<90 \mathrm{~mm} \mathrm{Hg}$ from 11 to 17 years.

From: Hugh Sampson, officially cited in EAACI position paper (60) 
tients who experienced an ALE after immunization can generally be safely reimmunised $(65,69)$. High-risk patients are those who have experienced a severe allergic reaction following immunisation. Anaphylaxis after vaccination is the only contraindication for vaccination in a standard care setting, but allergological investigation may provide alternative approaches for vaccine administration if the benefit of immunisation overweights the risks. Patients who reported a reaction to constituents of the vaccine or idiopathic anaphylaxis may also be at risk of AEFI, and therefore require an allergologist's evaluation to decide for subsequent vaccination schedule and setting. In patients with mastocytosis it is suggested to perform vaccination with single products and to extend observation time to 30 minutes at least, but a controlled setting is not usually required $(28,70)$.

Specific IgE antibodies to vaccine antigens are useless in the case of suspect hypersensitivity to the vaccine as they are produced in the normal immune response to immunisation, as mentioned above (43). On the other hand, serum tryptase level should be measured within 2 hours after a systemic severe vaccine reaction as a marker of anaphylaxis (28).

When suspecting an IgE-driven adverse reaction after vaccination, the allergological workup should first verify whether a sensitization to the vaccine and/or its component occurred. Table $\mathbf{V}$ summarizes vaccines' most important constituents and provides a quick guide for the clinician. Allergy testing is recommended regardless of the need for further immunizations (71). Several factors influence the sensitivity of in vivo tests. Besides individual features, time interval between the reaction and the allergological evaluation plays an important role. It may be advisable to perform skin tests at least 3 weeks after the reaction and no more than one year after the suspected IgE-mediated reaction. Of note, positive and negative predictive value of skin tests to vaccines has not been established yet.

Skin tests are performed on the volar surface of forearm and start with prick test with undiluted vaccine (or 1:10 dilution in case of reported anaphylactic reactions); if negative, intradermal tests (IDT) should be carried out with $0.02 \mathrm{ml}$ of 1:100 dilution and then, eventually, with 1:10 dilution. Positive (histamine) and negative (saline) controls have to be included. False positive irritant results may occur in 1:100 dilutions but they have mainly been described with IDT at 1:10 with influenza, MMR, varicella vaccines, and even more frequently with undiluted IDT, so that the latter is not recommended $(75,28)$. According to the patient's history and to the culprit vaccine, it is advisable to analyze even the vaccine components such as egg, gelatin and alpha-gal, latex and yeast through skin tests and/or specific IgE. When suspecting a type 4 mechanism in case of delayed local reactions after vaccination, diagnostic tests are not mandatory, because of the low risk of recurrence at revaccination, without contraindications for future immunization. However, patch test are easily-available, non-invasive tests which can confirm a di- agnosis of hypersensitivity to preservatives/stabilizers (e.g. thiomersal, phenoxyethanol, formaldehyde), adjuvants (aluminum) or antibiotics (e.g. aminoglycosides). Patch tests for phenoxyethanol or formaldehyde are standardised. Aluminum can be tested as metallic aluminium (using an empty Finn Chamber) or as aluminium chloride hexahydrate $2 \%$ in vaseline (using a plastic chamber). Late readings are needed after 3 or 4 days and after 7 days $(76,28)$. Unconventional approaches to diagnosis may still be useful in cases of severe anaphylaxis with negativity of in vivo tests and also when other concomitant therapies were ongoing at the time of reaction: Herreros et al. described the crucial role of BAT in determining the offending antigen (77).

\section{Revaccination of patients with suspected hypersensitivity reactions}

As a general rule, if the benefit of protection against pathogens outweighs the potential risk of reaction following immunization, the patient should undergo vaccine administration with a modified protocol or procedure. For example, in order to limit the incidence of local reactions, deeper injections and thigh instead of arm site of injections are preferable (78).

In the case of systemic and more severe reactions to vaccines requiring booster doses, administration should be preceded by blood tests aimed at evaluating if a protective IgG title has already been reached and it is stable. When there is no evidence of protection and a booster is needed, immunization with an alternative vaccine (not containing the allergenic component) may be performed. If an alternative product is unavailable, vaccination can proceed in a hospital setting with a i.v. line placed as follows: a) if skin tests result negative, a two-phase graded dose challenge can be injected (e.g. 10\% and 90\%, 30 minutes interval between the doses adopted from Kelso et al. and EAACI position paper); b) if prick or IDT confirm IgE hypersensitivity, a transient desensitization can allow administration of increasing doses of vaccine every 15 minutes (e.g. $0.05 \mathrm{ml}$ of 1:10 dilution, then undiluted solution starting from $0.05 \mathrm{ml}$, then 0.1 $\mathrm{ml}, 0.15 \mathrm{ml}, 0.2 \mathrm{ml}$ and for some vaccines $0.5 \mathrm{ml}$ ). Of note, the latest procedure cannot provide a permanent tolerance, therefore if other doses are required, desensitization should be carried out every time. In both cases patients should be observed for at least 60 minutes $(65,28)$. An alternative graded challenge was described by Seitz et al in 2009 (10\%, 30\% and 60\% of the normal vaccination dose) (66).

\section{Conclusions}

Allergic reactions after vaccinations are rare events. Since they can delay or even interrupt a regular vaccination plan, an allergological workup is required when a suspected immune-mediated AEFI occurs. The aims of the allergological evaluation are i) identifying or excluding hypersensitivity to vaccines, ii) se- 
Table $V$ - Vaccine content and advice for ALE management.

\begin{tabular}{|c|c|c|c|c|c|c|c|c|c|c|c|c|c|c|c|c|c|}
\hline & 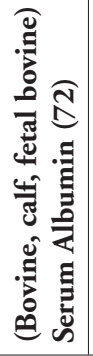 & 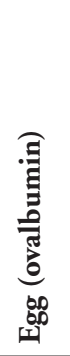 & $\stackrel{\breve{g}}{\stackrel{\Xi}{ే}}$ & 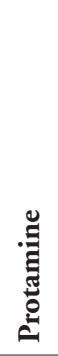 & 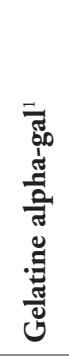 & 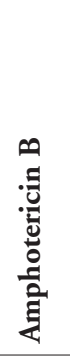 & 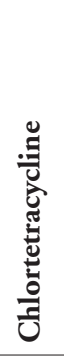 & 苞 & 氖 & 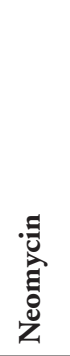 & 亮 & 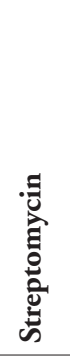 & 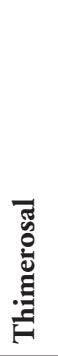 & 声 & 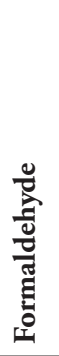 & 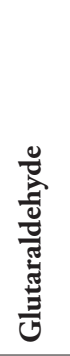 & 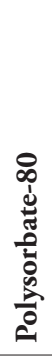 \\
\hline DTaP, Td, Tdap ${ }^{2}$ & $\boldsymbol{\Delta}$ & & $\boldsymbol{\Delta}$ & & 4 & & & & $\boldsymbol{\Delta}$ & $\boldsymbol{\Delta}$ & $\boldsymbol{\Delta}$ & & - & ○ & 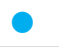 & - & $\Delta$ \\
\hline Hepatitis B $^{2}$ & & & $\boldsymbol{\Delta}$ & & & & & & $\boldsymbol{\Delta}$ & $\boldsymbol{\Delta}$ & & & & $\bullet$ & $\bullet$ & & $\Delta$ \\
\hline Hepatitis A & & & $\Delta$ & & & & & & $\Delta$ & $\Delta$ & & & & 0 & 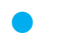 & & \\
\hline HPV & & & $\boldsymbol{\Delta}$ & & & & & & & & & & & $\bullet$ & & & $\Delta$ \\
\hline Influenza $^{2,5}$ & & 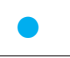 & & & 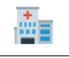 & & & $\Delta$ & $\Delta$ & $\Delta$ & $\Delta$ & & 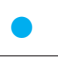 & & 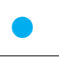 & & $\Delta$ \\
\hline JEV & $\Delta$ & & & $\Delta$ & 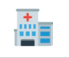 & & & & & & & & & $\bullet$ & ○ & & \\
\hline Meningococcal ${ }^{2,3}$ & & & $\Delta$ & & & & & & $\Delta$ & & & & 0 & 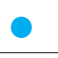 & 0 & & $\Delta$ \\
\hline $\mathbf{M M R}^{2}$ & & & & & 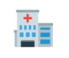 & & & & & $\Delta$ & & & & & & & \\
\hline PCV13 & & & $\Delta$ & & & & & & & & & & & 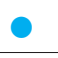 & & & $\Delta$ \\
\hline Polio & $\Delta$ & & & & & & & & & $\Delta$ & $\Delta$ & $\Delta$ & & & 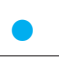 & & \\
\hline Rabies $^{2}$ & $\Delta$ & $\boldsymbol{\Delta}$ & & & 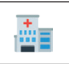 & $\boldsymbol{\Delta}$ & $\boldsymbol{\Delta}$ & & & $\Delta$ & & & & & & & \\
\hline Rotavirus $^{2}$ & $\Delta$ & & & & & & & & $\Delta$ & & & & & & & & $\Delta$ \\
\hline Typhoid fever $^{2}$ & & & $\Delta$ & & 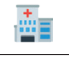 & & & & & & & & & & 0 & & \\
\hline Yellow fever & & $\Delta$ & & & 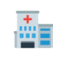 & & & & & & & & & & & & \\
\hline TBE & & & & $\Delta$ & & & & & & & & & & & & & \\
\hline Varicella/Zoster ${ }^{2}$ & $\Delta$ & & & & 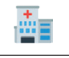 & & & & & $\Delta$ & & & & & & & $\Delta$ \\
\hline \multicolumn{18}{|c|}{$\begin{array}{l}\text { Caution should be used in parenteral administration of gelatin-containing products in patients with known alpha-gal hypersensitivity }(73) \text {; } \\
{ }^{2} \text { Different brands, compositions and associations; } \\
3 \text { Some contain DT as a carrier > contraindication in the case of a previous severe reaction to DtaP/DT/Td; } \\
{ }^{4} \text { Gelatin content prior to } 1997 \text { (ICON, 2016) (31) } \\
5 \text { According to AAP/COID guidelines egg allergy of any severity is not a contraindication to receive an influenza vaccine (including IIV) in a standard care setting (74 } \\
\text { JEV, japanese encephalitis virus }\end{array}$} \\
\hline
\end{tabular}

\begin{tabular}{|c|l|}
\hline $\boldsymbol{\Delta}$ & $\begin{array}{l}\text { general precautions unless a previous anaphylaxis } \\
\text { to the component was demonstrated }\end{array}$ \\
\hline & general precautions (GP, P or vaccination center) \\
\hline+ & controlled setting (hospital, Allergy Unit) \\
\hline
\end{tabular}

Data from: https://www.cdc.gov/vaccines/pubs/pinkbook/downloads/appendices/b/excipient-table-2.pdf

http://www.vaccinesafety.edu/components-Allergens.htm

https://www.cdc.gov/vaccines/pubs/pinkbook/downloads/appendices/B/latex-table.pdf lecting those subjects who require immunisation in specialized care settings and iii) ensuring access to vaccination. We propose a flow chart (figure 2) to assess an AEFI and particularly an ALE, providing specific clinical and laboratory tests, according to the onset and type of reaction and subsequent vaccination protocols. This work flow also comprises the management of patients with severe reactions to vaccine components and with idiopathic anaphylaxis. Finally, a screening questionnaire (table VI) might help the physician to decide whether an allergological workup and eventually a vaccination in a specialised care setting are advised. 


\section{Figure 2}

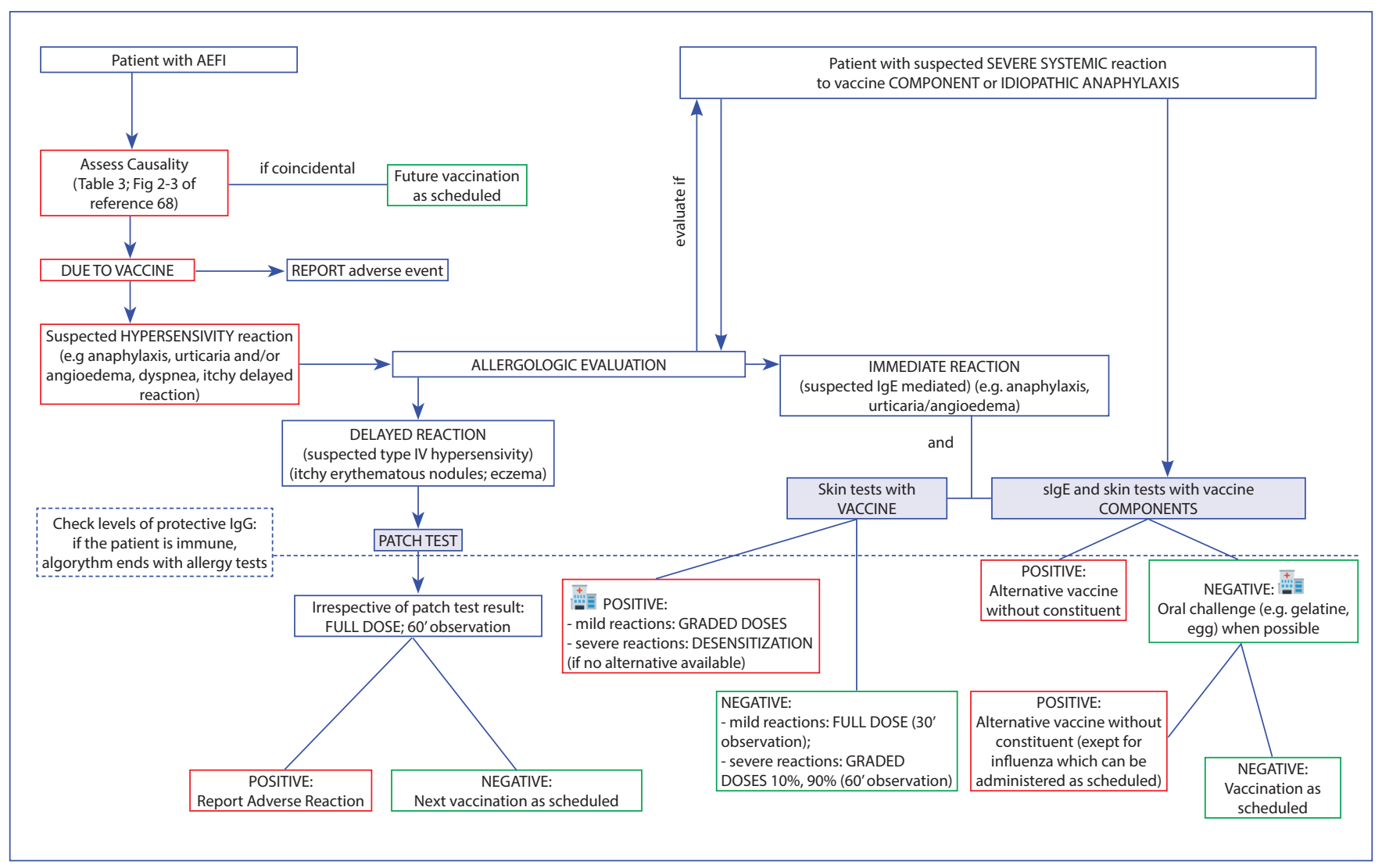

Figure 3 - Screening questionnaire for allergological evaluation in case of AEFI.

\begin{tabular}{|l|l|}
\hline PATIENT NAME: & DATE OF BIRTH: \\
\hline Vaccine name: & \\
\hline Indications for allergological evaluation before vaccines and for vaccination in specialised care setting \\
\hline
\end{tabular}

\begin{tabular}{|l|l}
\hline Previous vaccine reactions: & date:
\end{tabular}

$\square$ yes > vaccine name:

date:

$\square$ no

Previous idiopathic anaphylaxis:

$\square$ yes > date:

$\square$ no

Previous anaphylaxis associated to meat, gelatin or egg ingestion:

$\square$ yes > allergological workup: $\square$ yes $\square$ no

$\square$ no 


\section{References}

1. https://www.who.int/mediacentre/news/notes/2010/smallpox_20100517/en/ [Accessed December 2018].

2. http://www.epicentro.iss.it/problemi/vaiolo/vaiolo.asp [Accessed December 2018].

3. Delany I, Rappuoli R, De Gregorio E. Vaccines for the 21 st century. EMBO Mol Med 2014; 6(6):708-720.

4. Harper DM, DeMars LR. HPV vaccines - A review of the first decade. Gynecol Oncol 2017; 146(1):196-204.

5. Tract from: https://ec.europa.eu/ireland/news/vaccination-commission-calls-for-stronger-eu-cooperation-against-preventable-diseases_en

6. https://www.who.int/en/news-room/fact-sheets/detail/immunization-coverage [Accessed in December 2018].

7. Ozawa S, Clark S, Portnoy A, Grewal S, Brenzel L, Walker D.G. Return on investment from childhood immunization in lowand middle-income countries, 2011-20. Health Affairs 2016; 35(2):199-207.

8. https://www.gavi.org/about/value/cost-effective/ [Accessed in December 2018].

9. Zhou F, Santoli J, Messonnier ML, Yusuf HR, Shefer A, Chu SY, Rodewald L, Harpaz R. Economic evaluation of the 7-vaccine routine childhood immunization schedule in the United States, 2001. Arch Pediatr Adolesc Med 2005; 159(12):1136-1144.

10. Drolet M, Bénard É, Jit M, Hutubessy R, Brisson M. Model Comparisons of the Effectiveness and Cost-Effectiveness of Vaccination: A Systematic Review of the Literature. Value Health 2018; 21(10):1250-1258

11. Park M, Jit M, Wu JT. Cost-benefit analysis of vaccination: a comparative analysis of eight approaches for valuing changes to mortality and morbidity risks. BMC Med 2018; 16(1):139.

12. http://europa.eu/rapid/press-release_IP-18-3457_en.htm [Accessed in December 2018]

13. https://ec.europa.eu/health/vaccination/overview_en [Accessed in December 2018].

14. Damnjanović K, Graeber J, Ilić S, Lam WY, Lep Ž, Morales S, Pulkkinen T, Vingerhoets L. Parental Decision-Making on Childhood Vaccination. Front Psychol 2018; 9:735.

15. http://www.euro.who.int/_data/assets/pdf_file/0004/257575/ 64wd15e_EVAP_Rev1_140459.pdf [Accessed in January 2019].

16. https://ecdc.europa.eu/en/publications-data/annual-measles-and-rubella-monitoring-report-2017 [Accessed in December 2018].

17. Communicable Disease Threats Report, 15 December 2018 - EN. https://ecdc.europa.eu/en/publications-data/communicable-disease-threats-report-9-15-december-2018-week-50 [Accessed in December 2018].

18. World Health Organisation. MMR and autism. Available from http://www.who.int/vaccine_safety/committee/topics/mmr/mmr_ autism/en/ [Accessed in December 2018].

19. Ruiter, R. A., Kessels, L. T., Peters, G. J., and Kok, G. (2014). Sixty years of fear appeal research: current state of the evidence. Int J Psychol 49, 63-70.

20. https:/vaers.hhs.gov/data/dataguide.html [Accessed in December 2018].

21. Heininger U, Holm K, Caplanusi I, Bailey SM; CIOMS Working Group on Vaccine Safety. Guide to active vaccine safety surveillance: Report of CIOMS working group on vaccine safety - executive summary. Vaccine 2017; 35(32):3917-3392.
22. https://www.ema.europa.eu/en/committes/working-parties-other-groups/chmp/vaccines-working-party [Accessed in december 2018].

23. https://www.who.int/vaccine_safety/initiative/detection/AEFI/en/ [Accessed in January 2019].

24. https://www.who.int/vaccine_safety/publications/aevi_manual. pdf?ua $=1$ [Accessed in December 2018].

25. Demoly P, Adkinson NF, Brockow K, Castells M, Chiriac AM, Greenberger PA, Khan DA, Lang DM, Park H-S, Pichler W, Sanchez-Borges M, Shiohara T, Thong BY-H. International Consensus on drug allergy. Allergy 2014; 69:420-437.

26. Wood RA, Berger M, Dreskin SC, Setse R, Engler RJ, Dekker CL, Halsey NA; Hypersensitivity Working Group of the Clinical Immunization Safety Assessment (CISA) Network. An algorithm for treatment of patients with hypersensitivity reactions after vaccines. Pediatrics 2008; 122(3):e771-7.

27. WHO. Immunization Safety Surveillance Guidelines for immunization programme managers on surveillance of adverse events following immunization. 2013. 2nd edn. http://www.wpro.who. int/topics/immunization_safety/ImmunizationSafetySurveillance. pdf [Accessed January 2019].

28. Nilsson L, Brockow K, Alm J, Cardona V, Caubet JC, Gomes E, Jenmalm MC, Lau S, Netterlid E, Schwarze J, Sheikh A, Storsaeter J, Skevaki C, Terreehorst I, Zanoni G Vaccination and allergy: EAACI position paper, practical aspects. Pediatr Allergy Immunol 2017; 28(7):628-640.

29. Caubet Jean-Christoph, Ponvert Claude. Vaccine Allergy. Immunol Allergy Clin N Am 2014; 34:597-613.

30. www.hrsa.gov/vaccinecompensation/vaccineinjurytable.pdf [Accessed in January 2019].

31. Dreskin SC, Halsey NA, Kelso JM, Wood RA, Hummell DS, Edwards KM, Caubet JC, Engler RJ, Gold MS, Ponvert C, Demoly P, Sanchez-Borges M, Muraro A, Li JT, Rottem M, Rosenwasser LJ. International Consensus (ICON): allergic reactions to vaccines. World Allergy Organ J 2016; 9(1):32.

32. Rouleau I, De Serres G, Drolet JP, Skowronski DM, Ouakki M, Toth E, Landry M, Ménard S, Gagnon R. Increased risk of anaphylaxis following administration of 2009 AS03-adjuvanted monovalent pandemic A/H1N1 (H1N1pdm09) vaccine. Vaccine 2013; 31(50):5989-5996.

33. Nakayama T, Onda K. Vaccine adverse events reported in post marketing study of the Kitasato Institute from 1994 to 2004. Vaccine 2007; 25:570-576.

34. Erlewyn-Lajeunesse M, Hunt LP, Heath PT, Finn A. Anaphylaxis as an adverse event following immunisation in the UK and Ireland. Arch Dis Child 2012; 97(6):487-490.

35. McNeil MM, Weintraub ES, Duffy J, et al. Risk of anaphylaxis after vaccination in children and adults. JAllergy Clin Immunol 2016; 137:868-878.

36. Kawai AT, Li L, Kulldorff M, Vellozzi C, Weintraub E, Baxter R, et al. Absence of associations between influenza vaccines and increased risks of seizures, Guillain-Barre syndrome, encephalitis, or anaphylaxis in the 2012-2013 season. Pharmacoepidemiol Drug Saf 2014; 23(5):548-553. doi:10.1002/pds.3575.

37. D’Souza RM, Campbell-Lloyd S, Isaacs D, Gold M, Burgess M, Turnbull F, et al. Adverse events following immunisation associated with the 1998 Australian Measles Control Campaign. Commun Dis Intell 2000; 24(2):27-33.

38. Ozaki T, Nishimura N, Muto T, Sugata K, Kawabe S, Goto K, et al. Safety and immunogenicity of gelatin-free varicella vaccine 
in epidemiological and serological studies in Japan. Vaccine 2005; 23(10):1205-1208. doi:10.1016/j. Vaccine 2004.08.040.

39. Rutowski K, Ewan PW, Nasser SM. Administration of yellow fever vaccine in patients with egg allergy. Int Arch Allergy Immunol 2013; 161:274-278.

40. Myers TR, McNeil MM, Ng CS, Li R, Lewis PW, Cano MV Adverse events following quadrivalent meningococcal CRM-conjugate vaccine $\left(\right.$ Menveo $\left.^{\circledR}\right)$ reported to the Vaccine Adverse Event Reporting system (VAERS), 2010-2015. Vaccine 2017; 35(14):1758-1763.

41. Brotherton JML, Gold MS, Kemp AS, McIntyre PB, Burgess MA, Campbell-Lloyd S, on behalf of the New South Wales Health HPV Adverse events panel. Anaphylaxis following quadrivalent human papillomavirus vaccination. CMAJ 2008; 179:525-533.

42. Mark A, Björkstén B, Granström M. Immunoglobulin E responses to diphtheria and tetanus toxoids after booster with aluminium-adsorbed and fluid DT-vaccines. Vaccine 1995; 13:669-673.

43. Danneman A, Specific IgE and IgG4 immune responses to tetanus and diphtheria toxoid in atopic and nonatopic children during the first two years of life. Int Arch Allergy Immunol 1996; 111:262-267.

44. Nagao $\mathrm{M}$ et al. Highly increased levels of $\operatorname{IgE}$ antibodies vaccine components in children with influenza vaccine- associated anaphylaxis. J Allergy Clin Immunol 2016; 137:861-867.

45. Arroabarren E, Anda M, Sanz ML. Anaphylaxis to pneumococcal vaccine; CRM (197): novel cause of vaccine allergy. Pediatr Allergy Immunol 2016; 27:433-437.

46. Leung AK. Anaphylaxis to DPT vaccine. J R Soc Med 1985; 78:175.

47. Martin-Muñoz MF, Pereira MJ, Posadas S, Sanchez-Sabate E, Blanca M, Alvarez J. Anaphylactic reaction to diphtheria-tetanus vaccine in a child: specific $\operatorname{IgE} / \mathrm{IgG}$ determinations and cross-reactivity studies. Vaccine 2002; 20:3409-3412.

48. Kattan JD, Konstantinou GN, Cox AL, Nowak-Węgrzyn A, Gimenez G, Sampson HA, Sicherer SH. Anaphylaxis to diphtheria, tetanus, and pertussis vaccines among children with cow's milk allergy. J Allergy Clin Immunol 2011; 128(1):215-218.

49. Nelson MR, Oaks H, Smith LJ, Engler RJ. Anaphylaxis complicating routine childhood immunization: hemophilus influenza b conjugated vaccine. Pediatr Asthma, Allergy Immunol 2000; 14(4):315-321.

50. Stanley M, Lowy DR, Frazer I. Chapter 12: prophylactic HPV vaccines: underlying mechanisms. Vaccine 2006; 24(Suppl 3):S106-S113.

51. Badiu I, Geuna M, Heffler E, Rolla G. Hypersensitivity reaction to human papillomavirus vaccine due to polysorbate 80. BMJ Case Reports 2012.

52. Bigham M, Copes $\mathrm{R}$. Thiomersal in vaccines: balancing the risk of adverse effects with the risk of vaccine-preventable disease. Drug Saf 2005; 28(2):89-101.

53. Marc Baay, Kaatje Bollaerts, Thomas Verstraeten. A systematic review and meta-analysis on the safety of newly adjuvanted vaccines among older adults. Vaccine 2018. In press.

54. Di Miceli L, Pool V, Kelso JM, Shadomy SV, Iskander J, V.A.E.R.S. Team. Vaccination of yeast sensitive individuals: review of safety data in the US vaccine adverse event reporting system (VAERS). Vaccine 2006; 24:703-707.

55. Franceschini F, Bottau P, Caimmi S, et al. Vaccination in children with allergy to non active vaccine components. Clin Transl Med 2015; 4:3.
56. Parisi CAS, Smaldini PL, Gervasoni ME, Maspero JF, Docena GH. Hypersensitivity reactions to the Sabin vaccine in children with cow's milk allergy. Clin Exp Allergy 2012; 43:249-254.

57. Kwittken PL, Rosen S, Sweinberg SK. MMR Vaccine and Neomycin Allergy. Am J Dis Child 1993; 147:128-129.

58. Stone CA Jr, Hemler JA, Commins SP, et al. Anaphylaxis after Zoster vaccine: implicating alpha-gal as a possible mechanism. J Allergy Clin Immunol 2017; 139:1710-1713.

59. Siegrist CA. Mechanisms underlying adverse reactions to vaccines. J Comp Pathol 2007; 137(Suppl 1):S46-50.

60. Hugh Sampson, and used in the position paper in Allergy 2014. (Muraro A, Roberts G, Worm M, et al. Anaphylaxis: guidelines from the European Academy of Allergy and Clinical Immunology. Allergy 2014; 69:1026-1045.

61. Kroger AT, Duchin J, Vázquez M. General Best Practice Guidelines for Immunization. Best Practices Guidance of the Advisory Committee on Immunization Practices (ACIP). www.cdc.gov/ vaccines/hcp/acip-recs/general-recs/downloads/general-recs.pdf [Accessed on January 2019].

62. Santé et Services Sociaux du Québec. Protocole d'immunisation du Québec (PIQ) - Édition 6 Mises à jour de Novembre 2017. http:// publications.msss.gouv.qc.ca/msss/document-000105/ [Accessed on January 2019].

63. CDC Preventing and Managing Adverse Reactions https://www. cdc.gov/vaccines/hcp/acip-recs/general-recs/adverse-reactions.pdf [Accessed on January 2019].

64. Gordon SC, Bartenstein DW, Tajmir SH, Song JS, Hawryluk EB. Delayed-type hypersensitivity to vaccine aluminum adjuvant causing subcutaneous leg mass and urticaria in a child. Pediatr Dermatol 2018; 35(2):234-236.

65. Kelso JM, Greenhawt MJ, Li JT, Nicklas RA, Bernstein DI, Blessing-Moore J, et al. Adverse reactions to vaccines practice parameter 2012 update. J Allergy Clin Immunol 2012; 130:25-43.

66. Zafack JG, De Serres G, Rouleau I, Gariépy MC, Gagnon R, Drolet JP, Skowronski DM. Clinical Approach Used in Medical Consultations for Allergic-Like Events Following Immunization: Case Series Report in Relation to Practice Guidelines. J Allergy Clin Immunol Pract 2017; 5(3):718-727. e1.Epub 2016 Nov 30.

67. Sampson HA, Muñoz, Furlong A, Campbell RL, Adkinson NF, Bock A, Branum A et al. Second symposium on the definition and management of anaphylaxis: summary report. Second $\mathrm{Na}-$ tional Institute of Allergy and Infectious Disease/Food Allergy and Anaphylaxis Network symposium. J Allergy Clin Immunol 2006; 117:391-397.

68. A.E. Tozzi et al. Assessment of causality of individual adverse events following immunization (AEFI): A WHO tool for global use Vaccine 2013; 31:5041-5046.

69. Zafack JG, De Serres G, Kiely M, et al. Risk of Recurrence of Adverse Events Following Immunization: A Systematic Review. Pediatrics 2017; 140(3):e20163707

70. Zanoni G, Zanotti R, Schena D, Sabbadini C, Opri R, Bonadonna P. Vaccination management in children and adults with mastocytosis. Clin Exp Allergy 2017; 47:593-596.

71. Franceschini F, Bottau P, Caimmi S, Cardinale F, Crisafulli G, Liotti L, Pellegrini G, Peroni D, Saretta F, Mastrorilli C, Caffarelli C. Evaluating children with suspected allergic reactions to vaccines for infectious diseases. Allergy Asthma Proc 2018; 39(3):177-183.

72. De Silva R, Dasanayake WMDK, Wickramasinhe GD, Karunatilake C, Weerasinghe N, Gunasekera P, Malavige GN. Sensitization 
to bovine serum albumin as a possible cause of allergic reactions to vaccines. Vaccine 2017; 35(11):1494-1500. Epub 2017 Feb 16.

73. Stone CA, Commins SP, Choudhary S, Vethody C, Heavrin JL, Wingerter J, Hemler JA, Babe K, Phillips EJ, Norton AE. Anaphylaxis after vaccination in a pediatric patient: further implicating alpha-gal allergy. J Allergy Clin Immunol Pract 2019; 7(1):322-324.

74. Greenhawt M, Turner PJ, Kelso JM. Administration of influenza vaccines to egg allergic recipients: A practice parameter update 2017. Ann Allergy Asthma Immunol 2018; 120(1):49-52.

75. Wood RA, Setse R, Halsey N. Clinical Immunization Safety Assessment (CISA) Network Hypersensitivity Working Group. Irritant skin test reactions to common vaccines. J Allergy Clin Immunol 2007; 120:478-481.

76. Echeverría Zudaire L, Ortigosa del Castillo L, Alonso Lebrero E, Álvarez García FJ, Cortés Álvarez N, García Sánchez N, et al.
Documento de consenso sobre la actitud ante un niño con una reacción alérgica tras la vacunación o alergia a componentes vacunales. An Pediatr (Barc) 2015; 83:63.

77. Herreros B, Méndez Y, Feo-Brito F, Urra JM. Usefulness of basophil activation test for the diagnosis of IgE mediated hypersensitivity to tetanus toxoid vaccine. J Immunol Methods 2018; 454:8688. Epub 2017 Nov 21.

78. Jackson LA, Peterson D, Nelson JC, Marcy SM, Naleway AL, Nordin JD, et al. Vaccination site and risk of local reactions in children 1 through 6 years of age. Pediatrics 2013; 131:283289.

79. Seitz CS, Bröcker EB, Trautmann A. Vaccination-associated anaphylaxis in adults: diagnostic testing ruling out IgE-mediated vaccine allergy. Vaccine 2009; 27(29):3885-3889. Epub 2009 Apr 25. 